\title{
Survey Methodology for Estimating Patronage of High-Speed Rail in Korea
}

\author{
Jinsun Lee ${ }^{\dagger}$ and Doohee Nam*
}

\begin{abstract}
High-speed rail study needs to focus on passenger movements as a key element of the planning process. A particular challenge is obtaining comprehensive information on high-speed rail passenger movements. A national preference stated survey was conducted from October to November of 2011 to meet this challenge through direct personal interviews of travelers between Seoul and Busan (the so called Kyung-Bu corridor). Over 40 interviewers were hired and trained to conduct personal interviews at several stations along locations within Kyung-Bu Seoul and Busan corridor. A total of 4,550 travelers were interviewed, furnishing an extensive database on high-speed rail passenger movements. The methodology and procedure employed to collect the national data for Korean high-speed train KTX are described. Specific issues investigated include survey design, questionnaire and strategy. Lessons learned from the high-speed rail passenger movement study provide insights for other countries contemplating similar high-speed rail studies.
\end{abstract}

Keywords : High-speed rail, Stated preference survey, KTX

\section{Introduction}

After two decades of construction, Korean high-speed rail service known as KTX began operation along SeoulBusan corridor in 2004. The corridor linking the capital city of Seoul and the second-largest port city of Busan accounts for $66 \%$ of the country's passenger rail traffic, serves $72 \%$ of the population, and accounts for $77 \%$ of the gross domestic product.

The first trains carried passengers in April 2004 when electrification of the existing Daegu-Busan line was completed and was run at a maximum speed of $300 \mathrm{~km} / \mathrm{h}$. A new track for parts of the corridor near Busan was completed at the end of 2010, further shortening the time to traverse the corridor. With the system fully operational, the travel time between Seoul and Busan will be reduced to just under two hours. The total length of the new route is $412 \mathrm{~km}$ and each train, which is 387 meters long, has a seating for 935 passengers.

\footnotetext{
Corresponding author: Dept. of Railroad Business \& Management Woosong University, Korea

E-mail: jinsun@wsu.ac.kr

* Dept. of Information System Engineering Hansung University, Korea
}

The push to modernize Korea's railway system is gaining strength because of rising logistics costs due to road congestion, the quick development of high-speed rail, and demand for environment friendly transportation system. In addition to providing critically needed transport capacity in the Seoul to Busan corridor where over 70 percent of Korea's population and economic activity is concentrated, high-speed rail will be a key part of Korea's effort to ensure that its infrastructure will meet the country's development needs. The objective of this paper is to describe a survey procedure for estimating patronage of the highspeed rail service with the maximum speed of $300 \mathrm{~km} / \mathrm{h}$. The survey methodology based on direct personal interviews is described. Specific issues dealt with here include the selection of appropriate survey techniques, adequate sample sizes for surveying, determination of the information to be collected, design of the questionnaires, selection of survey stations, and scheduling of the survey. Additional issues include preparing interview team instruction as well as training. Finally, study findings of the research for planning practice are presented in the final section of the paper. 


\section{Survey Methodology}

Various forms of passenger demand models are reviewed but very little attention has been paid to the highspeed rail studies. The earliest models were of the direct demand type, and were developed in the 1960s. Recently used in high-speed rail studies was conducted in Florida, Southern California, Thailand, Taiwan and Australia. That was a multiplicative formulation of characteristics of the travel between current and future condition according to passengers' trip purposes. Disaggregate models typically use a logit formulation to provide a convenient way of including a number of mode, transportation accessibility, policy related variables in the modeling process. It was thought to be especially useful in the effort to estimate the shifts in mode share that were expected from deregulation in the air and intercity bus industries, and from the anticipated implementation of high-speed rail transportation.

The development of a methodology that would provide statistically reliable and comprehensive information on high-speed rail movements was needed to fulfill research goals outlined for the KTX study. However, planning for the efficient movement of high-speed rail is hindered by a lack of information on the source and characteristics of high-speed rail passenger movements. Obtaining comprehensive information on high-speed rail movements is more difficult because the KTX is completely different mode and not in service yet. So, travel data was gathered to support the forecasting process. Passenger travel surveys have been conducted at the national level since the earliest days of modeling. They are relatively expensive to conduct, however, and must be supplemented by other data. Stated preference is the most frequently chosen method to project the effects of service and fare changes. To accurately forecast high-speed rail ridership, stated preference surveys were conducted throughout the major corridor between Seoul and Busan in a manner designed to reach a broad sample of potential users of the passenger system. Stated preference data were collected through a travel survey to travelers would react to the availability of the planned high-speed rail transportation improvements as a traveling alternative. Stated preference survey can contribute to decision-making when past or current passenger response to fares and fare changes do not provide enough information about how patronage might respond to new types of fares under consideration. The same holds true for other types of transit service changes. Stated preference surveys are not simple "what would you do if" questionnaires, which have been largely discredited owing to their notorious inability to obtain reliable projection of behavior in response to changed conditions. They use carefully struc- tured sets of comparative questions, the responses to which are best analyzed within a probability modeling framework.

\section{Sampling Issues}

It was investigated that approximately $1,825,000$ passengers travels through the Kyung-Bu corridors each day. Interviewing every traveler, appearing about 2 million trips, in this busy corridor, is neither feasible nor necessary. Explicit description of objectives and criteria are required establishing sample sizes. In addition, information on known or suspected implementation issues can be used to increase the likelihood of successful implementation. Determination of sample sizes requires knowledge and consideration of monitoring objectives, desired levels of certainty in results and monitoring program duration as well as funding and logistics. To establish the appropriate sample size, detailed information are required such as all the estimates that will be produced from the survey, the precision desired for each estimate, knowledge of the variability expected and desired amount of detectable change. A reality faced in our studies is the budget and operational constraints. So, our survey was reassigned the priorities to survey objectives. Sample size calculations were conducted and approximately 4,550 surveys were completed using question-by-question interview approaches. Overall goal of obtaining at least 200 surveys per day was established. The surveys were administered during October and November at each survey station sites. Effective samples sizes consisted of 3,628 and the overall effective response rate was roughly $80 \%$. The highest response rate was for automobile and the lowest was for intercity bus.

\section{Determination of the Information}

Each form collected information on origin-destination, trip purpose, demographics, value of time for travel modes, value of frequency for the public modes. Travel options were organized in a manner that enabled respondents to consider trade-offs among travel attributes. These were presented in such a way as to induce individuals to give a realistic response to the options without bias to a specific mode of travel. For example, a problem frequently encountered is that many more people say they will use new high-speed train service than actually do. Some positive responses come from the desire to please the person taking the survey, while others represent an optimistic assessment of the service itself. Once the service is introduced, though, many will continue using their previous mode. Stated preference surveys ask travelers to 
choose between a hypothetical cost and another value, such as travel time and service frequency. This trade-off analysis isolates the main characteristics for travel choice without revealing what the correct answer might be.

\section{Questionnaire Design}

Questionnaire design is an important element of a successful methodology for high-speed rail passenger interviews. The national passenger survey collected information on time-of-day movements, origin and intended destination, travel frequency, travel objective, gender and household characteristics. To improve the response rate, the questionnaire was designed to be completed within 5 to 10 minutes. Approximately one-third of the questions were filled out by travelers themselves and remainder of the questions were interviewed through the trained interview personnel. Questions were asked directly to the potential high-speed rail passengers focused on travel time, fares, and intermodal transportation modes from their stated origin such as railroad station, domestic airports and intercity bus terminals to final destinations. Based on sample survey, the questionnaire was revised to request, "What is the reasonable fares and travel time between your stated origin and destinations?" Establishing a process for ongoing evaluation and modification to the survey questionnaire is essential.

Survey questions related to pairwise choices between high-speed rail transportation and the other modes such as airline, conventional rail, intercity bus and automobile. The first section of survey includes the traveler's socioeconomic characteristics and the travel behavior. Individual travel behavior is the study of what travelers do over space, and how they use transportation. For example, the questions are "How many trips do you make", "Where do you go", "What mode do you take", "When is the trip made", "What is the sequence of trips", "What route do you take", "Why do you travel". Next section, the questionnaire included stated-preference trade-off "experiment" which asked the respondents to choose between pairs of descriptions of varying service levels and fares for transit and auto alternatives. Finally, the survey was conducted in estimating the effect of a full range of travel time and fare structure modifications on different existing and potential ridership market segments. In this manner, as the respondent selected a preferred travel mode under the conditions described, several different travel time and fare levels were being tested.

The questions dealing with modal choice were binary choices questions. The questionnaire is made up of two exercises with binary choices questions by stages. First step corresponds to the line haul transportation during the Kyung-Bu corridor and the second step is the feeder transportation. In the first step, respondents may choose between high-speed rail and other modes such as conventional rail, airline, intercity bus or automobile. In the second step, respondents may choose between public mode and private mode in different travel times at different fares. In the latter, therefore, the travelers choose between time and cost for their daily journeys. Before estimating the utility functions, the observations on modal choice were weighted to reconstitute the actual distribution of travelers. Totally, 9 scenarios under the specific travel condition and 36 structured sets of comparative questions were given to travelers.

Respondents are presented with several transportation options and asked which option they would choose. By varying the travel time and fares, ridership for different combinations of attributes can be estimated. The main advantage of stated preference is their focus on traveler response to various options. The analysis can include whatever attributes are of interest, unconstrained by whatever survey respondents have ever experienced such services and fares. Major shortcomings of stated preference models limit their utility. These models typically overstate actual usage of new or improved high-speed rail services, often by large amounts. Other problem is that it is difficult to describe to respondents non-quantifiable attributes such as reliability of service. If this is true, it should be possible to deduce from direct questions the social desirability of public policy initiatives such as transportation improvements.

\section{Survey Stations}

The interviews were conducted at several survey stations. Railroad stations, domestic airports, intercity bus terminals and other commercial rest areas around the freeway were utilized as the primary data collection sites for this survey. On major corridors, multiple data collection sites were also identified. The specific railroad stations utilized as data collection sites which were identified through the expected high-speed rail station. To obtain a complete profile of high-speed rail passenger movements, it is necessary to interview the potential high-speed rail users traveling in both directions on a given major Kyung-Bu corridors. In total, interview sites were established at 8 railroad stations or in the rail cars, 6 domestic airports, 8 intercity bus terminals, and several commercial rest areas around the Kyung-Bu freeway. Especially, personal interviews to be conducted in the conventional rail were done by interviewers traveling in both directions on a Kyung$\mathrm{Bu}$ corridor. 


\section{Scheduling of the Survey}

The survey was conducted on Tuesdays, Wednesday, and Thursdays during October and November. The choice of month depended on whether typical or peak data were desired. The objective of this high-speed rail study was to obtain data for typical trip conditions. It revealed that traffic patterns in both October and November are generally considered typical in Korea. The choice of day of week also depended on the type of traffic. Interviews were consistently scheduled for Tuesdays or Thursdays to obtain median traffic patterns rather than exceptionally heavy Monday or Friday flows for weekdays. For weekend patterns, survey was scheduled for Saturdays and Sundays.

The KTX survey was developed data with an assumption that there are no seasonal differences in passenger movements except Thanksgiving (so called Chu-Seok) and other Holiday season. Data collection sites were systematically scheduled to avoid the multiple interviews on a given survey period. With this constraint, approximately one month was needed to complete the personal interview. The potential high-speed rail passenger interviews at survey locations were scheduled for a business hour period to provide a comprehensive picture of passenger movements.

\section{Interview Team Instruction \& Training}

Personal interviews allow the interviewer to clarify the questions and alternatives and to discuss the attitudes of the respondent. This is relatively expensive, but gives the best data and also gives the interviewers an intuitive feel that can later be compared to the mathematical model. To obtain the accurate movements throughout the Kyung-Bu corridor, it was necessary to conduct interviews simultaneously across the nation. Interview team training is always an important component of any study involving personal interviews, and a strong training program is essential. A detailed training program was conducted by a supervisor who was specially trained for the study. Each training session began with an overview of the key project goals and objectives so that interviewers would be prepared to answer basic questions from the potential highspeed rail passengers. The instructions guided the interviewers through the questions and specific detail needed in the response. Also, advice was offered on how to introduce the purpose of the KTX study and to request an interview from the potential high-speed rail passenger. Conducting personal interviews of the potential users at heavy traffic sites (in the intercity bus terminal or commercial rest area near the freeway) is a strenuous. However, direct interview surveys offer distinct advantages over self-reported data collection. So, the presence of an interviewer can increase response rate and make it possible for respondents to get immediate clarifications.

The training is the beginning of what should be a continuous process to ensure quality interviews. Later, most interviewers became highly adapt at conducting the personal interviews. However, periodic monitoring of interview activities continued throughout the survey. The main requirement for good interviewers is an ability to approach strangers in person and persuade them to participate in the survey. Data should be obtained in exact accordance with instructions. Training generally involves practice interviews to familiarize the interviewers with the variety of situations they are likely to encounter.

\section{Study Findings}

This final section highlights several lessons learned from the KTX study so that they can provide insights for other countries contemplating similar high-speed rail projects in the future. Finding cost-effective ways to increase transit ridership is a central goal for transportation agencies. Some of the questions that need to be answered are: How can travelers be attracted to the high-speed rail from conventional rail, automobile, intercity bus or airlines? What prospective service improvements, facility design, customer information, fare policies or other steps would make high-speed rail more attractive to customers? What is the importance of speed and reliability versus passenger comfort? How important are transit service levels of fares compared with external factors such as traffic congestion?

Stated preference surveys are surveys of actual or potential users, in which respondents are asked to express an attitude or make a choice as to how they would act under certain conditions. This survey can have a wide range of uses in transportation planning and can be tailored to understand very specific aspects of consumer behavior. KTX study was the most comprehensive one in Korea that collected nationwide data through direct personal interviews of the potential users. For high-quality data to be collected, interviewers were trained through instructions and self-study. The design and execution of the survey needs to consider the possible problem and a choice situation relating to the question.

The KTX study provides the framework for the survey and analysis. One of the most interesting parts of the KTX study was the utilization of direct interview method. Interview surveys offer distinct advantages over self-reported data surveys but are generally cost-effective only for lower volume (our sample size of 4,550). On average, an experienced interviewer can complete the questionnaire within 
15-20 minutes. A question-by-question approach is needed to make sure the interviewers can deal with various misunderstandings that may arise. In conclusion, besides being able to analyze the direct personal interviews associated with trip along a main corridor in Korea, the method used here are transferable to any country or region planning to introduce high-speed rail in the future.

\section{References}

1. Bates, J. (1988). Econometric issues in SP analysis, Journal of Transport Economics and Policy, Vol. 12, No. 1, pp. 5970.

2. Ben-Akiva, M. and S. R. Lerman, Discrete Choice Analysis: Theory and Applications to Travel Demand, MIT Press, Cambridge, Mass., 1991.

3. Bernardino, A., Ben-Akiva, M. and Salomon, I (1993). Stated preference approach to modeling the adoption of telecommuting, Transportation Research Record 1413, pp. 2241.

4. Casavant, Kenneth L., William R. Gillis, Dolly Blankenship, and Charles Howard, Jr. (1995). Survey methodology for collecting freight truck and destination data, Transportation Research Record 1477, pp. 7-14.

5. Gunn, H. F., Bradley, M. A. and D. A. Hensher (1992). High speed rail market projection: Survey design and analysis, Transportation 19, pp. 117-139.

6. Gunn, H. F., Bradley, M. A. and D. A. Hensher (1992). A modeling approach to the development of passenger forecasts for high-speed rail, HCG/Institute of Transport Studies.

7. Hensher, D. A., J., Brotchie and Gunn, H. F (1989). A methodology for investigating the passenger demand for highspeed rail, Proceedings of the 14th Australasian Transport Research Forum, Perth, pp. 117-139.

8. Louviere, J. J. (1988). Conjoint analysis modeling of stated preferences, Journal of Transport Economics and Policy. Vol. 12, No. 1, pp. 93-120.

9. Lyles, R. W. and J. H. Wyman, Traffic data-collection systems: current problems and future promise (Abridgment), Transportation Research Record 905, pp. 69-72.

10. NCHRP Synthesis of Transit Practice 16: Transportation Research Board, National Research Council, Washington, D.C. (1991), pp. 13-34.

11. Sheffi, Y. Urban Transportation Planning. Prentice-Hall, Englewood Cliffs, N.J., 1985.

12. Stopher, P. R., Metcalf, Helen M. A., Wilmot, Chester G., Catalina, Anthony J. and Charles C. Schimpeler (1999). Estimating patronage for a feasibility study of high-speed rail in thailand, Transportation Research Record 1691, pp. 12-18.

13. Wardman, M (1991). Stated preference methods and travel demand forecasting: An examination of the scale factor problem. Transportation Research A, Vol. 25A, Nos. 2-3, pp. 79-89.

Received(May 23, 2011), Revised(June 20, 2011),

Accepted(June 24, 2011) 